\title{
Gerak Relationship pada Permainan Tradisional Anak Sunda sebagai Sumber Penciptaan Komposisi Tari Anak
}

\author{
Ayo Sunaryo $^{\varpi_{1}}$, Juju Masunah ${ }^{2}$, Tati Narawati ${ }^{3}$, Trianti Nugraheni ${ }^{4}$ \\ Pendidikan Tari, Universitas Pendidikan Indonesia \\ DOI: $10.31004 /$ obsesi.v4i2.499
}

\begin{abstract}
Abstrak
Gerak relationship terdapat dalam koreografi permainan tradisional anak Sunda, yaitu koreografi yang saling berhubungan atau bersentuhan antara satu pemain dengan pemain lainnya atau pemain dengan kelompok, gerakan ini hampir ada pada semua permainan radisional anak Sunda yang dikenal dengan nama kakawihan dan kaulinan. Tujuan penelitian ini menganalisis koreografi relationship pada permainan anak Sunda dan dijadikan sebagai sumber penciptaan komposisi tari anak. Artikel ini adalah hasil penelitian dengan menggunakan paradigma kualitatif deskriptif analisis dengan pendekatan analisis dasar elemen tari BSTER (Body, Space, Time, Energy, Relationship) melalui teknik pengumpulan data, observasi, pengamatan, dan wawancara yang telah di triangulasi dan diintepretasi. Hasil penelitian ini adalah adanya gerak relationship pada sebagian besar koreografi permaianan tradisional anak di Indonesia dan bisa dijadikan sumber dalam penciptaan komposisi tari anak. Gerak relationship pada permainan tradisional anak mengandung nilai silih asih, silih asah dan silih asuh yang merupakan ciri sosial pada masyarakat di Indonesia.
\end{abstract}

Kata Kunci: gerak relationship; permainan tradisional sunda; komposisi tari anak

\begin{abstract}
Relationship motion is found in the choreography of traditional Sundanese children's games, namely choreography that is interconnected or touching one player with another player or player with a group, this movement is found in almost all traditional Sundanese children's games known as kakawihan and kaulinan. The purpose of this research is to analyze the relationship choreography of Sundanese children's games and serve as a source for the creation of children's dance compositions. This article is the result of research using a descriptive qualitative analysis paradigm with a basic analysis approach to the dance element BSTER (Body, Space, Time, Energy, Relationship) through data collection, observation, observation, and interview techniques that have been triangulated and interpreted. The results of this study are the existence of relationship in most traditional children's choreographies in Indonesia and can be used as a source in the creation of children's dance compositions. Relationship motion in children's traditional games contains values of love, love, and care for children which is a social characteristic of people in Indonesia.
\end{abstract}

Keywords: motion; relationship; traditional sundanese chidrens game.

Copyright (c) 2020 Ayo Sunaryo, Juju Masunah, Tati Narawati, Trianti Nugraheni

$\triangle$ Corresponding author :

Email Address : ayosekolah@upi.edu (Jl. Dr. Setiabudhi No. 229 Bandung, Indonesia)

Received 23 March 2020, Accepted 1 April 2020, Published 3 April 2020 


\section{PENDAHULUAN}

Gerak relationship adalah gerakan yang saling berhubungan antara orang dengan orang, orang dengan set, orang dengan benda lainnya (McCutchen, 2006). Pola gerakan ini hampir semuanya terdapat dalam permainan tradisional anak Sunda di Indonesia, terutama dalam permainan tradisional yang terdapat koreografi bakunya (oray-orayan, slepdur, cingciripit, dll). Permainan tradisional anak terdiri dari gerak-gerak elemen dasar tari yang membentuk koreografi. Konsep Body, Space, Time Energy, Relationships (BSTER) merupakan elemen dasar tari yang saling berhubungan dalam membentuk koreografi. Relationship merupakan bagian dalam elemen dasar tari yang mengacu pada hubungan yang harus dilakukan oleh bagian tubuh penari dengan segala objek (McCutchen, 2006). Salah satu konsep yang terdapat dalam koreografi permainan tradisional anak Sunda adalah aspek relationship. Koreografi ini merupakan hubungan antara bagian tubuh pemain dengan pemain lainnya. Studi tentang relationship membuat penari sadar akan lingkungan dan ruang yang ada di sekitarnya. Pemain atau penari membiasakan diri untuk menjadi dekat dan bergerak dalam kaitannya dengan sesuatu, misalnya: penari dengan penari lain, sekelompok penari, benda mati, set dan properti, penonton atau ruang itu sendiri (McCutchen, 2006).

Penelitian tentang permainan tradisional terlebih kepada konteksnya sudah banyak diteliti. Studi ini membahas perbedaan antara permainan masa kecil orang tua dan preferensi permainan anak-anak mereka. Hasil penelitian menunjukkan bahwa permainan tradisional yang dilakukan oleh orang tua mereka pada masa kecil sangat berpengaruh pada kehidupan sosial daripada anak-anak mereka yang bermain sering bermain game elektronik di dalam rumah, (Balci \& Ahi, 2017).

Hubungan antara menari dan bermain bagi anak-anak (6-8 tahun) dalam pendidikan tari di lima kota di Swedia menunjukkan bahwa ada hubungan antara bermain dan menari, karena anak-anak kecil tertarik pada "aksi dan dalam karakter" angka, peran dan tindakan. Namun, sebagian besar pelajaran tari dari lima kota di Swedia melakukan pelatihan gerak dalam kaitannya dengan musik, dan tarian bukanlah subjek yang dramatis dari aksi permainan anak-anak (Lindqvist, 2001).

Penelitian yang diterbitkan oleh Turkish Folklore Research and Application Center 2007 tentang pemainan anak-anak tradisional yang bertahan di Turki, menemukan bahwa permainan dan mainan tradisional pada umumnya digantikan oleh mainan yang sebagian besar terbuat dari plastic dan dikembangkan oleh industri mainan. Sementara boneka kain dan mobil logam yang dulunya sebagai mainan populer, hari ini mobil, boneka, robot, dan permainan komputer yang dikendalikan dari jarak jauh telah menjadi lebih populer di kalangan anak-anak (Yavuzer, 1993 dalam (Balci \& Ahi, 2017). Permainan tradisional anakanak pada intinya adalah kesenangan, lebih dari itu bisa sumber daya moral pendidikan yang kuat dan pemersatu antara anak-anak dari budaya yang berbeda (Andreu-Cabrera, 2009). Permainan tradisional anak di Indonesia, menunjukan nilai- nilai kebaikan seperti kejujuran, kedisiplinan, kepatuhan, keindahan, kebersamaan, toleransi, tenggang rasa, tanggung jawab, kepemimpinan, kesadaran, kearifan, kekuatan fisik, dan sportifitas. Proses pengembangan karakter berpijak pada aspek mengenal alam, mengenal lingkungan, dan mengenal Tuhan, dilakukan dengan upaya memperkenalkan, memahami, dan mengajarkan melalui cara pembiasaan dan keteladanan (Diantama, 2018). Permaian tradisional yang ada di di Indonesia sangatlah beragam, khususnya di Provinsi Jawa Barat permainan itu dinamakan dengan kaulinan dan kakawihan (Kosasih, 2012). Pada suku Baduy-Dalam (Provinsi Banten) disebut dengan pagawean barudak (Alif, Sachari, \& Sabana, 2015). Dalam konteks ini, permainan tradisional anak yang dimaksud adalah kaulinan dan kakawihan. Permainan tradisional anak ini adalah cerminan kearifan lokal manusia Sunda yang sejalan dengan nilai-nilai universal manusia umumnya, yaitu: gembira, gotong royong, menghargai, kerjasama, mengasihi, perjuangan, suka, duka, baik, buruk, benar, salah, hidup, maut, dan benar. Unsur-unsur tersebut merupakan sesuatu yang alamiah yang merupakan suatu jalinan peristiwa yang terpadu dan sering ditemukan dalam kehidupan (Sunaryo, 
2009). Pendapat lain mengatakan bahwa permainan anak memiliki aturan dan dapat mengalami banyak emosi, seperti kebahagiaan, kegembiraan, kesedihan, ketakutan, kecemasan, dendam, kebencian, cinta, ketergantungan, kemandirian dan perpisahan saat bermain (Akandere, 2003 dalam Balci \& Ahi, 2017).

Kakawihan dan kaulinan termasuk pada folklor lisan yang berbentuk nyanyian rakyat, karena kakawihan ini sering dinyanyikan masyarakat Sunda terutama anak-anak pada saat mereka bermain dengan teman-temannya (Gloriani, 2013). Permaianan tradisional anak Sunda biasanya memiliki koreografi yang sudah baku. Adapun bentuk permainan anak tersebut adalah oray-orayan, slepdur, endog-endogan, cingciripit, paciwit-ciwit lutung, saslimpetan, ucang-ucang angge,dan hompimpa. Permainan tradisional tersebut adalah permaianan yang biasa dilakukan anak-anak, geraknya tentu sesuai dengan kemampuan anak-anak, mereka bisa bebas bergerak Tetapi, sebenarnya secara tidak sadar mereka sedang melakukan koreografi pada sebuah tarian. Itulah mengapa menari untuk anak kecil harus dikaitkan dengan permainan anak-anak (Lindqvist, 2001). Permainan dapat didefinisikan sebagai hiburan dengan aturan yang memungkinkan individu untuk bersenang-senang mengembangkan keterampilan dan kecerdasan. Keberadaan permainan itu sendiri sudah setua sejarah manusia dan telah bertahan hingga saat ini (Huizinga, 1955).

Permaian anak Sunda di atas, tentu saja mengandung unsur koreografi, teks dan konteks. Teks yang dimaksud dalam penelitian ini adalah bentuk-bentuk koreografi yang terdapat dalam Permainan Anak Sunda. Pendekatan "teks" dapat dilakukan dengan menganalisis bentuk, teknik dan gaya secara koreografis atau telaah secara struktural dan analisis secara simbolik. Adapun yang dimaksud dengan "konteks" adalah bagian imanent dan integral dari dinamika sosio-kultural masyarakat (Hadi, 2017).

Gerak relationship terdapat dalam koreografi permainan tradisional anak Sunda, yaitu koreografi yang saling berhubungan atau bersentuhan antara satu pemain dengan pemain lainnya atau pemain dengan kelompok. Gerak relationship ini dilakukan bersamaan dengan nyanyian, bisa tangan bersentuhan dengan tangan, jari bersentuhan dengan jari, kaki bersentuhan dengan kaki dan badan bersentuhan dengan anggota tubuh yang lainnya. Gerak relationship ini jika disatukan maka akan terbentuk koreografi yang bisa saja diartikulasikan sebagai sebuah tarian dengan bahan dasar gerak permainan, karena menari adalah aktivitas mengartikulasikan (Bacon \& Midgelow, 2010). Hubungan spasial antara penari atau antara penari dan objek adalah dasar untuk konsep desain seperti di samping, di depan, di atas, di atas, di sekitar, di dekat, dekat atau jauh (Aldis \& Muench, 2018).

Pada penelitian ini, gerak relationship harus dilihat secara langsung dengan menggunakan pemain supaya materi koreografi dapat dianalisis dengan jelas, jika hanya menggunakan rekaman atau video maka materi koreografi tidak akan terlihat dengan jelas. Sebuah karya koreografi meninggalkan sesuatu yang lebih dari jejak atau fragmen di belakang dalam memori, maka itu bukan koreografi menari. Materialitas tarian terikat dengan dimensi immaterialnya sendiri. Ini adalah fitur normatif dari tarian dan dokumentasinya dimana kehadiran dan vitalitas penari menjadi hampir klise, yaitu rekaman video tidak pernah bisa menjadi hal yang nyata (Derrida, Franko, Badiou, \& Resources, 2003).

Pengukuran konsep relationship pada permainan tradisional anak Sunda harus bisa diukur dengan menggunakan konsep teori komposisi BSTER yang mana relationship ini merupakana bagian dari teori ini, sehingga setiap gerakan harus dijelaskan dan diukur dengan teknik-tehnik komposisi tari. Melalui teori komposisi tarian, gerakan dapat diatur sebagai koreografi, sehingga keberhasilan dapat dipahami dan diukur (Triana, 2015). Tujuan penelitian ini menganalisis koreografi relationship pada permainan anak Sunda dan dijadikan sebagai sumber penciptaan komposisi tari anak 


\section{METODOLOGI}

Metode yang dipergunakan adalah metode kualitatif deskriptif analisis Terlebih dahulu dilakukan seleksi atau pemilihan bahan yang akan dijadikan materi analisis, yaitu permainan anak Sunda yang dinamakan kakawihan dan kaulinan. Adapun bentuk permainan tersebut adalah permainan oray-orayan, endog-endogan, cingciripit, slepdur, perepet jengkol, ucang-ucang angge, paciwit-ciwit lutung, dan sasalimpetan.

Bentuk-bentuk kaulinan dan kakawihan tersebut kemudian ditetapkan sebagai bahan materi untuk di analisis elemen dasar tarinya. Adapun langkah-langkah pemilihan materi permainan tradisional anak Sunda ini adalah sebagai berikut.

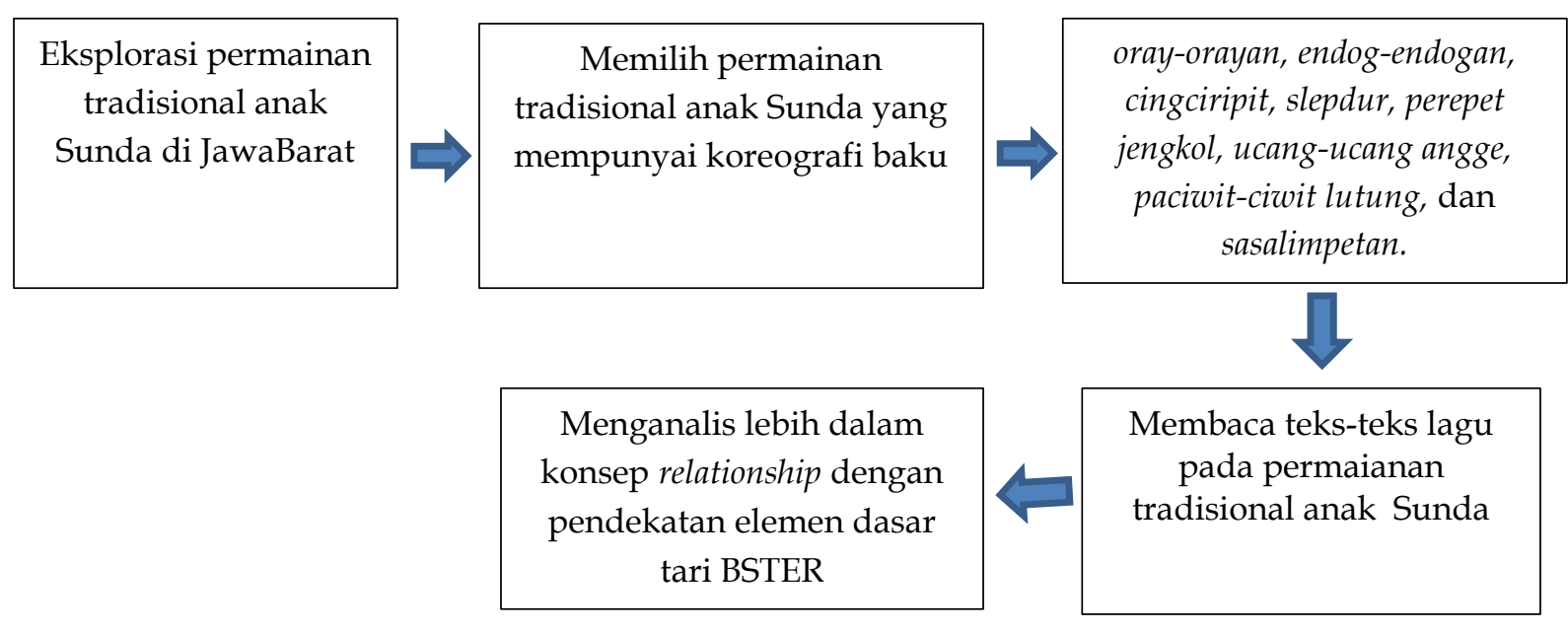

\section{Gambar 1 \\ Syntax Pemilihan Materi Permainan Tradisional Anak Sunda}

Penelitian ini memfokuskan pada bentuk-bentuk permainan anak yang sudah mempunyai koreografi baku yang sudah ada sejak dahulu. Hal ini dilakukan karena peneliti akan membahas dari aspek koreografi sebagai teks.

\section{HASIL DAN PEMBAHASAN}

Jika dikaji dari aspek koreografi, maka bentuk-bentuk permaianan tersebut memiliki aspek-aspek dasar koreografi yang dapat dianalisis melalui elemen dasar tari BSTER (Body, Space, Time, Energy, Relationship). Pada buku Teaching Dance As Art In Education, menjelaskan konsep Body, Space, Time, Energy dan Relationship (McCutchen, 2006). Konsep pertama dinamakan dengan konsep Body, terdiri dari a). bagian-bagian tubuh, seperti: kepala (head), leher (neck), torso (torso), dada (chest), dan lain sebagainya. Kedua adalah konsep Space, terdiri dari: direction, size, phatway, levels. Konsep ini termasuk ke dalam aksi (action) yang terdiri dari gerak berpindah (locomotor) dan gerak ditempat (non locomotor/axial movement). Konsep ketiga dinamakan dengan konsep Time, seperti waktu sequence, duration, tempo), rhytms, beat, accent, unpredictable. Konsep keempat dinamakan dengan konsep Energy. Energi yang terdiri dari flow, force, tense, weight, strong, smooth, tight, loose, heavy, light, sudden. Konsep Kelima adalah Relationship adalah konsep lain yang menyatu dengan konsep ruang (space). Ciri dari gerakan ini adalah gerakannya saling berhubungan dengan yang lainnya, yaitu hubungan antara Hubungan dengan audien, lingkungan hidup, hubungan dengan panggung dan set, pasangan, hubungan antara 2 orang, benda, hubungan dengan alat peraga tertentu, kelompok, hubungan antara seluruh kelompok. Konsep relationship ini akan dijadikan sebagai bahasan utama, karena konsep ini hampir terdapat dalam semua permainan tradisional anak Sunda. 
Dari beberapa permaianan anak Sunda yang ada, maka akan dipilih beberapa bentuk permainan tradisional anak Sunda yang mempunyai konsep gerak relationship, sebagai berikut.

Tabel 1

Gerak Relationship Pada Permainan Tradisional Anak Sunda

\begin{tabular}{|c|c|c|c|c|c|c|}
\hline \multicolumn{4}{|c|}{ B.S.T. E.R DANCE ELEMENT } & \multirow{2}{*}{ Relation } & \multirow{2}{*}{ Deskripsi } & \multirow{2}{*}{ Permainan } \\
\hline Body & Space & Time & Energy & & & \\
\hline $\begin{array}{l}- \\
\text { Standing } \\
- \\
\text { Locomoto } \\
r \\
\text { (walking) }\end{array}$ & $\begin{array}{l}\text { trough space, } \\
\text { size-large, } \\
\text { shape-circular, } \\
\text { direction- } \\
\text { forward, } \\
\text { phatway- } \\
\text { circle), focus- } \\
\text { front, level- } \\
\text { medium. }\end{array}$ & $\begin{array}{l}\text { Tempo- } \\
\text { medium- } \\
\text { beat, } \\
\text { duration- } \\
\text { sustained). } \\
\text { prasing- } \\
\text { sequence }\end{array}$ & $\begin{array}{l}\text { Light, } \\
\text { flow, } \\
\text { loose, } \\
\text { relax. }\end{array}$ & $\begin{array}{l}\text { Tangan } \\
\text { menyentuh } \\
\text { (touch) } \\
\text { dengan cara } \\
\text { mencengkr } \\
\text { am } \\
\text { (gripping) } \\
\text { pundak } \\
\text { (shoulder) } \\
\text { pemain di } \\
\text { depannya } \\
\text { secara } \\
\text { horizonal. } \\
\text { Body part to } \\
\text { group. }\end{array}$ & $\begin{array}{l}\text { Permainan Oray-orayan } \\
\text { (oray=ular) dimainkan } \\
\text { secara berkelompok, } \\
\text { biasanya oleh 10-20 anak } \\
\text { yang berbaris dari } \\
\text { belakang ke depan } \\
\text { berbentuk garis kurva } \\
\text { bentuk dari ular. Sambil } \\
\text { memegang pundak } \\
\text { temannya yang ada di } \\
\text { depan, mereka meliuk- } \\
\text { liuk. } \\
\text { Oray-orayan } \\
\text { Luar leor ka sawah } \\
\text { Entong kasawah } \\
\text { Parena keur sedeng beukah } \\
\text { Oray-orayan } \\
\text { Luar leor ka kebon } \\
\text { Entong ka kebon } \\
\text { Di kebon loba nu ngangon } \\
\text { Mending ka leuwi } \\
\text { Di leuwi loba nu mandi } \\
\text { Saha anu mandi? } \\
\text { Anu mandina pandeuri }\end{array}$ & Oray-Orayan \\
\hline $\begin{array}{l}- \\
\text { Standing } \\
- \\
\text { Locomoto } \\
r \\
\text { (walking }\end{array}$ & $\begin{array}{l}\text { trought space, } \\
\text { size-large, } \\
\text { shape-spiral, } \\
\text { direction- } \\
\text { forward, } \\
\text { phatway- } \\
\text { circle, focus- } \\
\text { front, level- } \\
\text { medium }\end{array}$ & $\begin{array}{l}\text { Light, flow, } \\
\text { loose, relax }\end{array}$ & $\begin{array}{l}\text { Tempo- } \\
\text { medium, } \\
\text { beat, } \\
\text { duration- } \\
\text { sustained } \\
\text {, pattern- } \\
\text { sequence, } \\
\text { accent. }\end{array}$ & $\begin{array}{l}\text { Tangan } \\
\text { (hand) } \\
\text { memegang } \\
\text { tangan } \\
\text { (hand) } \\
\text { pemain } \\
\text { lainnya } \\
\text { dengan } \\
\text { gerak } \\
\text { lengan } \\
\text { (arm) secara } \\
\text { menyayun } \\
\text { (swinging). } \\
\text { Body part to } \\
\text { group. }\end{array}$ & $\begin{array}{l}\text { Permainan sasalimpetan } \\
\text { merupakan kakawihan } \\
\text { dan kaulinan barudak } \\
\text { lembur yang bermain } \\
\text { sambil berpegangan } \\
\text { tangan. Kemudian kepala } \\
\text { dari barisan masuk pada } \\
\text { ruang badan kedua } \\
\text { pemain yang saling } \\
\text { berpegangan tangan, } \\
\text { disusul dengan pemain } \\
\text { yang lainya sehingga } \\
\text { terlihat seperti pola } \\
\text { spiraL. } \\
\text { Sasalimpetan jajahan aing } \\
\text { nu panjang, hey hey } \\
\text { Aki janggotan tumpak kuda } \\
\text { heheotan } \\
\text { Sasalimpetan jajahan aing } \\
\text { nu panjang, hey hey } \\
\text { Aki janggotan tumpak kuda } \\
\text { heheotan knda heheotan. } \\
\text { Tumpak kuda } \\
\text { Tumpak kuda heheotaaaaan. } \\
\text { Tumpak kuda heheotan. }\end{array}$ & Sasalimpetan \\
\hline
\end{tabular}




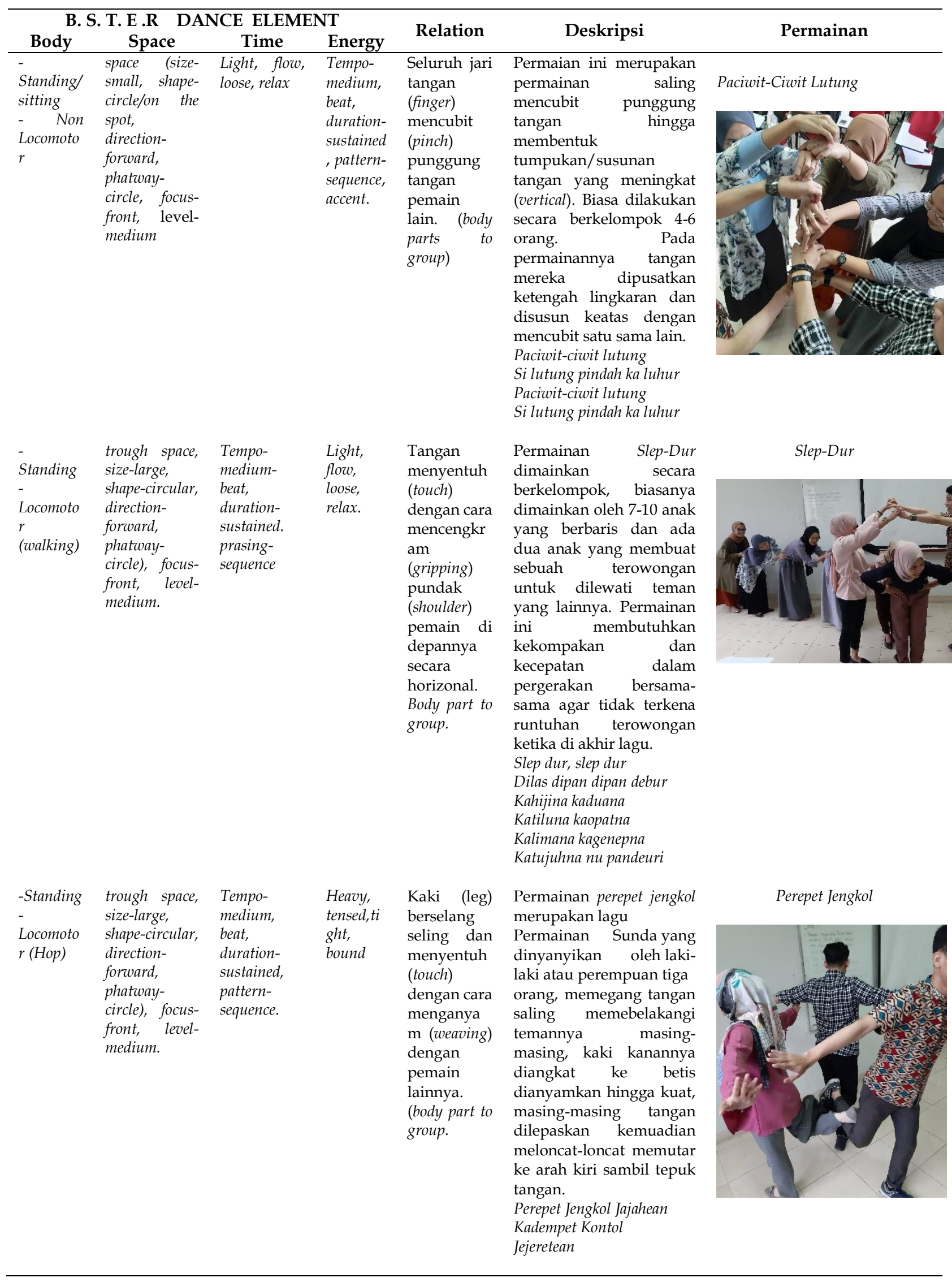


DOI: 10.31004/obsesi.v4i2.499

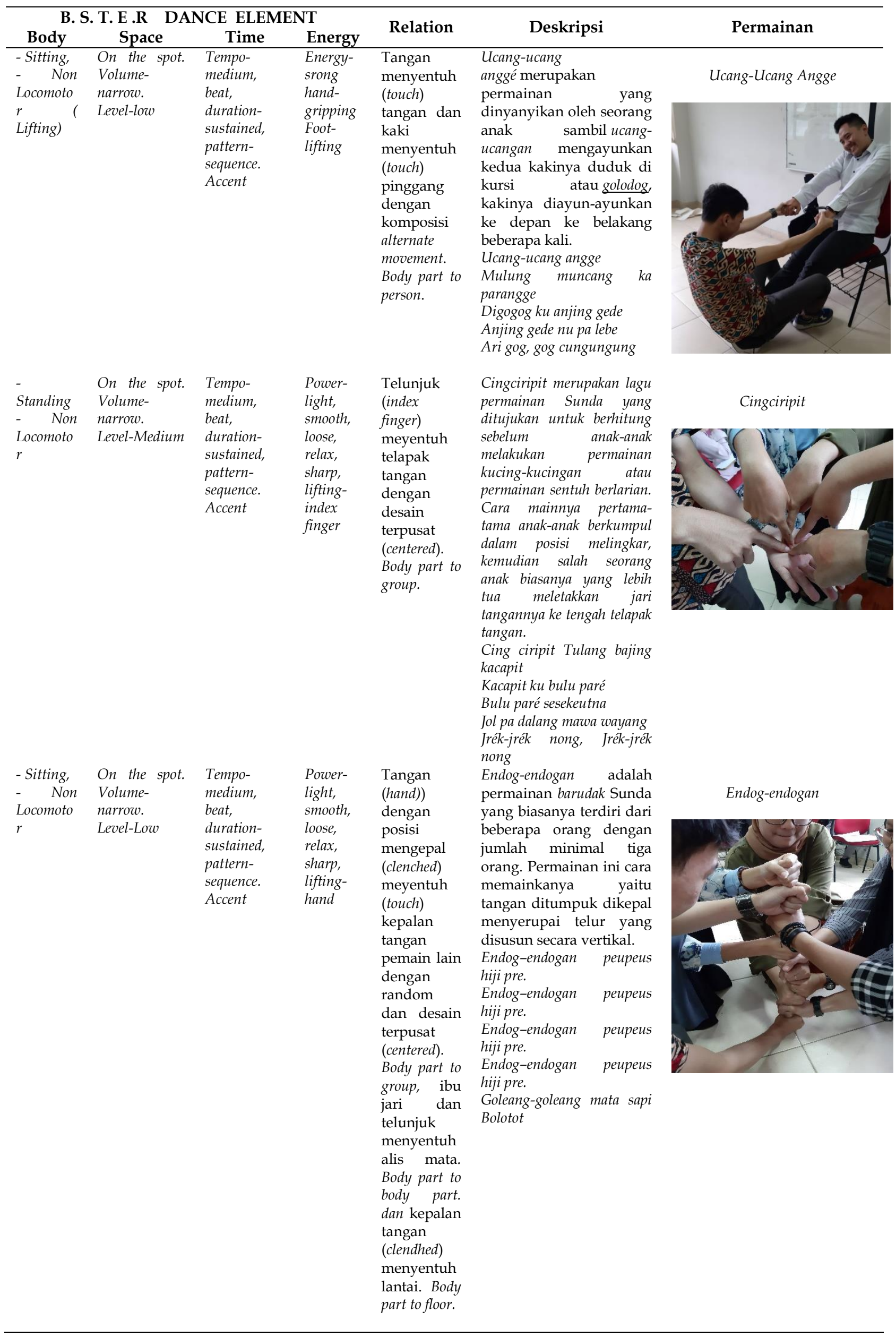


Permainan tradisional anak Sunda pada umumnya dilakukan diluar luar ruangan atau di halaman rumah. dalam konteks tari koreografi yang dilakukan termasuk ke dalam konsep dance site yang selalu merespon ruang termasuk merespon tubuh lainnya. Relationship ada antara tubuh dan ruang ketika manusia merespon ruang di sekitar mereka. Hubungan tubuh-ruang ini sebagai salah satu perwujudan dari permainan tradisional anak Sunda memiliki potensi besar untuk melibatkan kelompok, mengaktifkan ruang publik, dan memengaruhi perubahan. Dengan menempatkan tarian dalam pengalaman hidup, termasuk permaian tradisional memberdayakan mengenali peran mereka sebagai agen aktif yang membentuk entitas ruang yang tidak statis, dan karenanya dapat digunakan untuk menciptakan hubungan baru ke tempat-tempat dalam suatu komunitas (Baines, 2016). Pada konteks ini, berhubungan dengan penelitian Mulvihill tentang kolaborasi yang menyatakan bahwa kolaborasi merupakan aktivitas antara penata tari, tarian dan lingkungannya sehingga bisa menjadikan warganegara yang bertanggung jawab (Mulvihill, 2018). Dalam idenya tentang tubuh transaksional, Sullivan (2001) menempatkan penekanan pada kebiasaan dan kemampuan beradaptasi dengan lingkungan. Shotter (2010) menyimpulkan bahwa untuk ada relasional antara pandangan dialogis tentang kehidupan. Aktivitas seperti ini terdapat pada permaianan tradisional anak Sunda yang selalu membangun kolaborasi antara sesama pemain dan lingkungannya.

Relationship dalam konteks permaianan tradisional anak merupakan konsep hubungan keruangan yang menghubungkan seseorang dengan objek lainnya. Ruang dan tubuh sebagai produksi spasial ruang terpisah dari aktivitas spasial, ruang yang dialami dan dibangun oleh tubuh tampak lebih akrab daripada ruang yang dihasilkan hanya melalui sudut pandang satu orang. Dengan demikian saat menyelidiki hubungan antara tubuh dan ruang, menjadi penting untuk memahami sub-hubungan yang mempengaruhi posisi tubuh di ruang Ruang dapat didefinisikan sebagai jaringan gerakan potensial yang terdiri dari bidang-bidang tarian seperti tubuh, gerakan, dan keseimbangan. Interaksi ruang-tubuhtarian, dengan penerimaan ruang yang mewakili berbagai pengalaman (Gümüştaş, 2015).

Relationship dalam permainan tradisional anak Sunda merupakan proses improvisasi yaitu pemain melakukan improvisasi dengan objek lainnya secara berkelompok dan menghasilkan koreografi dengan emosional yang sangat dalam. Hal ini merupakan proses komunikasi non-verbal yang tidak berwujud. Selama improvisasi, penari harus memahami emosi satu sama lain. Kerja kelompok dianggap berharga serta kemampuan untuk mengaktifkan sinergi untuk mencapai keharmonisan. Ini adalah bentuk komunikasi yang lebih canggih dan lebih dalam daripada komunikasi verbal karena produk tidak berwujud. (Biasutti, 2013). Permainan tradisional anak Sunda biasanya dilakukan secara berkelompok atau juga dilakukan dengan dua orang pemain (duet), tetapi, tidak lepas dari gerak relationship yang menghubungkan satu pemain dengan pemain lainnya atau dengan kelompok. Hal ini menunjukan aspek kerjasama dan saling ketergantungan dengan orang lain sangat penting dan diperlukan untuk kinerja timbal balik yang efektif (Majoroos, 2008).

Semua permainan anak yang telah diungkapkan di atas, yaitu permainan oray-orayan, endog-endogan, cingciripit, perepet jengkol, slepdur, paciwit-ciwit lutung, sasalimpetan, dan ucangucang angge memiliki konsep relationship (touch). Dalam teori koreografi gerak yang saling menyentuh/sentuhan disebut juga dengan body contact. Teknik gerak body contact merupakan teknik gerak yang diterapkan dengan cara bersentuhan, bisa antara tangan dengan bahu, tangan dengan tangan ataupun pinggang dengan kaki. Pada teori Touch of Mind sentuhan merupakan kemampuan manusia untuk berkomunikasi dengan yang lainnya. Para peneliti telah lama mendokumentasikan emosi dan keinginan kompleks yang diungkapkan oleh postur gerakan dan ekspresi manusia (Belbase, 2013).

Relationship adalah sentuhan, salah satu elemen terpenting dari perkembangan manusia, metode komunikasi yang mendalam, komponen penting kesehatan dan pertumbuhan bayi, dan kekuatan penyembuhan yang kuat (Zur \& Nordmarken, 2009). Dalam karya seminarnya, Touching: The Human Significance of the Skin, Ashley Montagu 
menyatukan sejumlah besar studi yang menyoroti peran kulit dan sentuhan fisik dalam perkembangan manusia. Dia melanjutkan dengan menjelaskan bagaimana sistem sensorik, kulit, adalah sistem organ tubuh yang paling penting, karena tidak seperti indera lainnya, manusia tidak dapat bertahan hidup tanpa fungsi fisik dan perilaku yang dilakukan oleh kulit. Dari semua indera, sentuhan merupakan yang terpenting. Selanjutnya, ia mengatakan bahwa sentuhan sering disebut sebagai "ibu dari semua indera" karena ini adalah indra pertama yang berkembang dalam embrio, dan semua indera lainnya-penglihatan, suara, rasa, dan bau berasal darinya. Dalam tiga minggu konsepsi, kami telah mengembangkan sistem saraf primitif yang menghubungkan sel-sel kulit ke otak kita yang belum sempurna. Sentuhan sering disebut sebagai ibu dari semua indera karena ini adalah indra pertama yang dikembangkan dalam embrio (Montagu, 1986).

Jika mencermati pendapat di atas, ternyata sentuhan pada permainan anak memiliki peranan penting, karena merupakan sensor utama yang tumbuh dalam embrio dan mempengaruhi indra yang lain. Sentuhan-sentuhan (touch) dalam koreografi permainan tradisional anak Sunda. Pendapat lain mengatakan bahwa Pada saat kita dewasa, kebanyakan dari kita telah belajar bahwa menyentuh cenderung meningkatkan emosi, terutama ketika datang ke rasa konektivitas. Bahkan kontak singkat dengan orang asing dapat memiliki efek yang terukur, baik membina dan meningkatkan kerja sama (Chillot, 2013). Pendapat tersebut di atas menegaskan bahwa sentuhan pada gerak relationship pada koreografi permainan anak dapat meningkatkan sensitivitas sensor-sensor tubuh bagian lainnya juga dapat meningkatkan konektivitas atau rasa kerja sama dengan yang lainnya.

Dalam konteks masyarakat Suku Sunda di Indonesia terdapat kearifan budaya membangun kehidupan manusia dengan meletakkan pentingnya keharmonisan hubungan antar manusia dalam kehidupan masyarakat yang hidup saling ketergantungan dengan tidak melupakan jatidiri dan habitatnya untuk meningkatkan kualitas kemanusiaan, terdapat dalam konsep silih asih, silih asah, dan silih asuh. Perpaduan kata silih dengan masing-masing kata asih, asah, asuh menjadikan kata majemuk mengandung makna transformasi nilai yang bersumber dari subtansi makna nilai: asih, asah, asuh dalam kehidupan antar manusia dalam realitas kehidupan masyarakat, sehingga terbangun harmonisasi yang saling ketergantungan untuk meningkatkan kualitas kemanusiaan, Kata silih dalam masyarakat Sunda digunakan dalam pemikiran tradisional mereka, yakni: Silih asih: saling mengasihi antar sesama, Silih asah: saling menajamkan pikiran dan saling mengingatkan, Silih asuh: saling mengasuh dan saling membimbing. (Suryalaga, 2010 dalam Saleh, Soejadi dan Lasiyo, 2013). Pada konteks budaya, masyarakat merupakan lingkungan sekitar anak yang sangat berpengaruh juga terhadap perkembangan anak. Faktor budaya juga memberikan dampak yang besar untuk anak usia dini yang sedang berkembang karena dengan budaya anak belajar dan dengan budaya pula anak berkembang (Nafsia \& Supena, 2020).

Bermain juga menciptakan makna. Signifikansi permainan terletak pada maknanya, yang mencerminkan kenyataan di tingkat yang lebih dalam, dan tidak boleh ditafsirkan sebagai presentasi realistis dari tindakan tertentu. Karena anak memiliki kapasitas untuk menciptakan situasi imajiner atau cerdik, ini juga mendukung pemikiran abstrak. Tidak ada pertentangan antara estetika dan rasionalitas, imajinasi dan kenyataan (Lindqvist, 2001). Gerak relationship menciptakan makna yang selalu saling berhubungan dan ketergantungan antar manusia yang satu dengan yang lainnya sehingga tercipta sikap gotong royong, menghargai, kerjasama, mengasihi, perjuangan, sengsara, suka, duka, baik, buruk, benar, salah, hidup, maut, dan benar. Unsur-unsur tersebut merupakan sesuatu yang alamiah yang merupakan suatu jalinan peristiwa yang terpadu dan sering ditemukan dalam kehidupan (Sunaryo, 2009). Relationship dalam konteks tari berarti manusia adalah makhluk sosial yang menginginkan hubungan dengan manusia lainnya (Hogan, Sides, \& Kemp, 2017). Bukan saja berhubungan dengan manusia, asyarakat Sunda dalam kebudayaannya memiliki kemampuan menghayati karakter setiap unsur alam sebagai pelajaran yang kemudian 
dijadikan sebagai pengandaian dalam memandang diri dan manusia lain (Indrawardana, 2013). Selain itu, gerak yang saling berhubungan pada kakawihan dan kaulinan barudak adalah nilai untuk mengenal alam, budaya dan Tuhan (Mayakania, 2013). Permainan tradisional anak ini dilakukan secara berkelompok sehingga keterampilan sosial anak terjadi ketika anak bermain, berkomunikasi dan bekerasama dengan teman lainnya (Sari, Yetti, \& Supena, 2019).

\section{SIMPULAN}

Gerak relationship yang dilakukan dengan sentuhan (touch) yang terdapat pada koreografi permainan anak dapat meningkatkan sensitivitas sensor-sensor tubuh bagian lainnya juga dapat meningkatkan konektivitas atau rasa kerja sama anak-anak. Konsep relationship merupakan ciri sosial masyarakat Sunda dalam membangun keharmonisan hubungan antar manusia untuk meningkatkan kualitas kemanusiaan, yakni: Silih Asih: saling mengasihi antar sesama. Silih Asah: saling menajamkan pikiran; saling mengingatkan. Silih Asuh: saling mengasuh; saling membimbing. Gerak relationship pada kakawihan dan kaulinan barudak menjadi sumber yang berlimpah pada penciptaan komposisi tari anak. Koreografi pada kakawihan dan kaulinan barudak bisa dikembangkan oleh guru, tetapi tidak menghilangkan koreografi aslinya.

\section{UCAPAN TERIMAKASIH}

Terimakasih kami ucapkan kepada semua pihak yang berperan dalam proses penelitian ini. Terutama kepada segenap Ketua Departemen dan civitas akademika Departemen Pendidikan Tari FPBS, UPI, tempat penulis melakukan penelitian, kepada tiga orang Profesor pembimbing dan para mahasiswa angkatan 2016. Ucapan terima kasih juga disampaikan kepada tim editor Jurnal Obsesi yang telah memberikan saran, kritik, dan rekomendasi untuk perbaikan artikel ini.

\section{DAFTAR PUSTAKA}

Aldis, D., \& Muench, G. (2018). The Elements of Dance. 2009. Retrieved from https://www.elementsofdance.org

Alif, M. Z., Sachari, A., \& Sabana, S. (2015). Konsep Desain Venakular Dalam Bentuk pagawéan barudak di Baduy-Dalam. Panggung, 25(4), 391-404. https:// doi.org/10.26742/ panggung.v25i4.46

Andreu-Cabrera, E. (2009). Traditional Chilren's Games In The Mediterranean : Analogi. Journal of Human Sport and Exercise, 8(2), 486-487. https://doi.org/10.4100/jhse

Bacon, J. M., \& Midgelow, V. L. (2010). Articulating choreographic practices, locating the fi eld: An introduction and what What boundaries are contemporary choreographers. Choreographic Practices, 1, 3-19. https:/ / doi.org/10.1386/chor.1.3

Baines, L. (2016). Dance, Embodiment, and Cultural Ecology: The Reflexive Relationship Between Bodies and Space. Congress on Research in Dance Conference Proceedings, 2016(May), 1-8. https://doi.org/10.1017/cor.2016.1

Balci, S., \& Ahi, B. (2017). Mind the gap! Differences between parents' childhood games and their children's game preferences. Contemporary Issues in Early Childhood, 18(4), 434-442. https://doi.org/10.1177/1463949117742788

Belbase, S. (2013). A Unified Theory of Mind-Brain Relationship: Is It Possible? Open Journal of Philosophy, 03(04), 443-450. https:// doi.org/10.4236/ojpp.2013.34065

Biasutti, M. (2013). Improvisation in dance education: teacher views. Research in Dance Education, 14(2), 120-140. https:// doi.org/10.1080/14647893.2012.761193

Chillot, R. (2013, March). The Power of Touch. Psycholgy Today.

Derrida, J., Franko, M., Badiou, A., \& Resources, I. (2003). Constructing Memories Creation of the choreographic resource s cot t de la h $\mathrm{u} n$ ta a $\mathrm{d} \mathrm{n}$ o r a h z u n i g a s haw. Centrum, 1. 
Diantama, S. (2018). Sundanese Traditional Games in Building the Character of. Citizenship Jurnal Pancasila Dan Kewarganegaraan, 6, no.1. https://doi.org/http://doi.org/10.25273/citizenship.v6i1.1871

Firdaus Saleh, Soejadi, dan L. (2013). Makna "Silas" Menurut Kearifan Budaya Sunda Perspektif Filsafat Nilai: Relevansinya Bagi Pemberdayaan Masyarakat Miskin. Sosiohumaniora, 15(2), 178. https://doi.org/10.24198/sosiohumaniora.v15i2.5745

Gloriani, Y. (2013). Kajian Nilai-Nilai Sosial Dan Budaya Pada Kakawihan Kaulinan Barudak Lembur Serta Implementasinya Dalam Pembelajaran Bahasa Dan Sastra Indonesia Berbasis Multikultural. Jurnal Lokabasa, 4(2). https:// doi.org/10.17509/jlb.v4i2.3147

Gümüştaş, E. H.-S. (2015). Time, Space + Body The Choreography of Space with Body Esin Hasgül Saime Gümüsştaş. (September), 1-14.

Hadi, S. (2017). Koreografi. Bentuk-Teknik-Isi (Cetakan Ke). Yogyakarta: Cipta Media.

Hogan, B. S. K., Sides, R., \& Kemp, S. (2017). Today's relationship dance customer loyalty. Delotte. University Press, (20). Retrieved from https://dupress.deloitte.com/dup-us-en/deloittereview/issue-20/behavioral-insights-building-long-term-customer-loyalty.html

Huizinga, J. (1955). Homo Ludens: A Study of the Play Element in Culture. Boston: Beacon Press.

Indrawardana, I. (2013). Kearifan Lokal Adat Masyarakat Sunda Dalam Hubungan Dengan Lingkungan Alam. Komunitas: International Journal of Indonesian Society and Culture, 4(1), 18. https:// doi.org/10.15294/komunitas.v4i1.2390

Kosasih, D. (2012). Nilai-Nilai Yang Terkandung Dalam Kakawihan Barudak Sunda: Persepsi dan Realitas Kebahasaan. Prosiding Konfrensi International Budaya Daerah Ke-2 Denpasar Bali. Bali. Indonesia: Pustaka Larasan.

Lindqvist, G. (2001). The Relationship between Play and Dance. Research in Dance Education, 2(1), 41-52. https:// doi.org/10.1080/14647890120058302

Majoroos, K. (2008). The relationship of couples in competitive dancing. Journal of Human Sport and Exercise, 3(2), 12-24. https://doi.org/10.4100/jhse.2008.32.02

Mayakania, N. D. (2013). Internalisasi Nilai-nilai Pendidikan Karakter melalui Kakawihan Kaulinan Barudak Buhun di Komunitas Hong Bandung. Jurnal Panggung, 23(4). https://doi.org/10.26742/panggung.v23i4.156

McCutchen, B. P. (2006). Teaching Dance as Art in Education. Champaign. United Sates: Human Kinetics.

Montagu, A. (1986). Touching; The Human Significance of the Skin (Thrid Edit). New York: Harper \& Row.

Mulvihill, J. A. (2018). COLLABORATION: An Activity of Responsible Citizenship. Journal of Dance Education, 18(3), 112-119. https://doi.org/10.1080/15290824.2018.1481963

Nafsia, A., \& Supena, A. (2020). Jurnal Obsesi: Jurnal Pendidikan Anak Usia Dini Pembentukkan Karakter Anak Usia Dini melalui Budaya Nalo di Kampung Lodo Abstrak. 4(2), 703-714. https://doi.org/10.31004/obsesi.v4i2.439

Sari, M., Yetti, E., \& Supena, A. (2019). Peningkatan Keterampilan Sosial melalui Kegiatan Tari Saman. Jurnal Obsesi: Jurnal Pendidikan Anak Usia Dini, 4(1), 1. https://doi.org/10.31004/obsesi.v4i1.240

Shotter, J. (2010). Social Construction on the Edge: Withness-Thinking and Embodiment (C. Falls, Ed.). New York: Taos Institute Publications.

Sullivan, S. (2001). Living Across and Through Skins: Transactional Bodies, Pragmatism and Feminism. Bloomington: Indiana University Press.

Sunaryo, A. (2009). Internalisasi Nilai-nilai Tradisi pada Penciptaan Tari Anak Berbasis Budaya Lokal. Jurnal Ilmiah. Retrieved from http://jurnal.upi.edu/file/Ayo_Sunaryo.pdf

Triana, D. D. (2015). The Ability of Choreography Creative Thinking on Dance Performance. Harmonia: Journal of Arts Research and Education, 15(2), 119-125. https://doi.org/10.15294/harmonia.v15i2.4555

Zur, O., \& Nordmarken, N. (2009). To Touch Or Not To Touch: Exploring Prohibition On Touch In Psychotherapy And Counseling and the Ethical Considerations of Touch. Zur Institute, 1-39. Retrieved from https://www.zurinstitute.com/touchintherapy.html 